\title{
Anopheline species composition and the 1014F-genotype in different ecological settings of Burkina Faso in relation to malaria transmission
}

\author{
Alphonse Traoré ${ }^{12^{*}} \mathbb{0}$, Athanase Badolo ${ }^{1,2}$, Moussa W. Guelbeogo ${ }^{1}$, Antoine Sanou1, Mafalda Viana ${ }^{4}$, Luca Nelli $^{4}$,
} Soumanaba Zongo ${ }^{1}$, Hyacinthe K. Toé ${ }^{1}$, Alfred S. Traoré2 ${ }^{2}$ Hilary Ranson ${ }^{3}$ and N'Falé Sagnon ${ }^{1}$

\begin{abstract}
Background: A three-year longitudinal study was conducted in four sentinel sites from different ecological settings in Burkina Faso, between 2008 and 2010 to identify longitudinal changes in insecticide resistance within Anopheles gambiae complex species based on larval collection. During this study, adult mosquitoes were also collected indoor and outdoor using several methods of collection. The present study reports the diversity of malaria vectors and the 1014F-genotype from this adult collection and investigates the association between this 1014F-genotype and sporozoite rate.

Methods: Adult mosquitoes were collected from July to August (corresponding to the start of rainy season) and October to November (corresponding to the end of rainy season) over 3 years (2008-2010) at four sites across the country, using pyrethrum spray catches (PSC), exit traps and pit shelters. Anopheles gambiae complex mosquitoes were identified to species and genotyped for the L1014F kdr mutation by PCR using genomic DNA. The circumsporozoite antigen of Plasmodium falciparum was detected in mosquitoes using sandwich ELISA.

Results: Overall 9212 anopheline mosquitoes were collected during the study period. Of those, 6767 mosquitoes were identified as Anopheles gambiae sensu lato (s.l.). Anopheles arabiensis, Anopheles coluzzii, Anopheles gambiae and or Anopheles funestus were incriminated as vectors of $P$. falciparum in the study area with an average sporozoite rate of 5\%, (95\% Cl 4.14-5.99\%). The kdr1014F-genotype frequencies were $11.44 \%$ (95\% Cl 2.5-39.85\%), 19.2\% (95\% Cl 4.53-53.73\%) and 89.9 (95\% Cl 63.14-97.45\%), respectively for An. arabiensis, An. coluzzii and An. gambiae. The proportion of the 1014F-genotype varied between sporozoite-infected and uninfected An. gambiae s.l. group. There was no significant difference in the 1014F-genotype frequency between infected and uninfected mosquitoes.

Conclusion: The current study shows the diversity of malaria vectors and significant interaction between species composition and kdr1014F-genotype in An. gambiae complex mosquitoes from Burkina Faso. In this study, no associations were found between the 1014F-genotype and P. falciparum infection in the major malaria vector An. gambiae s.l.
\end{abstract}

Keywords: Malaria, Diversity, Anopheles gambiae, Plasmodium falciparum, kdr, Insecticide, Resistance

\footnotetext{
*Correspondence: traorealphonse@yahoo.fr

${ }^{2}$ Laboratoire d'Entomologie Fondamentale et Appliquée, Université

Ouaga1 Pr Joseph Ki-Zerbo, BP 7021 Ouagadougou 03, Burkina Faso

Full list of author information is available at the end of the article
} 


\section{Background}

After decades of efforts to malaria control, this disease is still a major public health concern in sub-Saharan Africa, responsible for an estimated of 219 million cases and 435,000 deaths in 2017 [1]. Burkina Faso is a malaria endemic country with 19 million inhabitants, where nearly 12 million malaria cases were reported in 2017 with 4144 resulting in death [2]. In Burkina Faso, malaria prevention primarily relies on insecticide-treated bed nets. In 2010, 2013 and 2016 combined, approximately 36 million long-lasting insecticide-treated nets (LLINs) were freely distributed through mass distribution campaigns. Additional sporadic measures such as Indoor Residual Spraying (IRS) with bendiocarb were introduced in 2010 in Diébougou, a locality situated in the southwestern part of Burkina Faso but this pilot programme was terminated in 2011 (http://www.africairs.net/where-we-work/burki na-faso/). A larviciding pilot programme using Bacillus thuringiensis was also implemented for 1 year in 2012 to control malaria in Ouagadougou the capital city of Burkina Faso.

Anopheles gambiae, Anopheles coluzzii, Anopheles arabiensis and Anopheles funestus are the most important malaria vectors in Burkina Faso [3, 4]. Members of the An. gambiae complex are sympatric species with different ecological niches $[5,6]$. Previous studies showed that the species composition of the An. gambiae complex varied across Burkina Faso climatic conditions. Whilst Anopheles arabiensis and An. coluzzii are distributed with equal frequency in central and eastern regions of the country [7], the western regions, where rainfall is abundant, are dominated by An. gambiae sensu stricto (s.s) $[5,8]$. Anopheles arabiensis is the most abundant species found in urban compared to rural areas [6]. Recently a new cryptic sub-group inside An. gambiae, named Goundry, was identified in Burkina Faso [9] with an exophilic behaviour.

The development of resistance to insecticides in malaria vectors is one of the main concerns for malaria control as to date major vector tools rely on insecticide use. In Burkina Faso, resistance to the four major classes of insecticides (organochlorides, organophosphates, pyrethroids and carbamates) used in public health has recently increased throughout the country. The resistance level to pyrethroids is particularly high in the Western region of the country [10-12], which may affect bed nets efficacy [13]. Four mechanisms of insecticide resistance have been described in West Africa [14, 15]. One of the most widespread mechanisms is target site mutation associated with resistance to pyrethroids and DDT [16] in the voltage-gated sodium channel, associated with knock down resistance $(k d r)$ alleles. Three $k d r$ mutations have been reported in the An. gambiae complex: L1014F, L1014S and N1575Y [17-19]. There is increasing evidence that insecticide pressure used in public health and agriculture is leading to the selection of insecticide resistance in malaria vectors [13]. The 1014F $k d r$ allele frequency is very high in An. gambiae and An. coluzzii in Burkina Faso, while the $1014 S$ is very common in An. arabiensis [10, 12, 20].

There is little empirical data on the impact of insecticide resistance on malaria transmission but modeling has predicted that widespread resistance to pyrethroids will result in additional 260,000 deaths in children under 5 years of age [21] in the WHO African Regions. Insecticide resistance is assumed to increase the likelihood of mosquito-borne disease transmission by increasing the vector population size and allowing mosquitoes a long period of life even the presence of insecticides [22]. On the other hand, resistance may reduce the vectorial capacity by imposing a major fitness cost to mosquitoes [22], but laboratory experiments have suggested that mosquito strains with the $k d r$ mutation were more susceptible to Plasmodium infection [23]. However, it has also been reported that older Anopheles mosquitoes are more susceptible to insecticides than newly-emerged ones [24-27]. Hence, if insecticide resistant mosquitoes are more susceptible to infection with the malaria parasite, then the chances to transmit malaria parasite in areas with intensive insecticide exposure may be diminished, according to Viana et al. [28]. In contrast, a previous laboratory experiments showed that mosquitoes resistant to pyrethroids may be more susceptible to $P$. falciparum infection, and thus could potentially be more efficient malaria vectors [29]. Thus, field studies are needed to establish whether there is any association between insecticide resistance and the ability of the mosquito to transmit the malaria parasite (i.e. the presence of sporozoites in the mosquito's salivary glands).

A three-year longitudinal study was conducted in Burkina Faso between 2008 and 2010 to assess for longitudinal changes in insecticide resistance from larval collections and results were published in Badolo et al. [10]. In addition, during this study, adult mosquitoes were also collected indoor and outdoor in different ecological settings with different levels of insecticide resistance. The objectives of this work were to report on the species diversity of malaria vectors in these different ecological settings of Burkina Faso and the association between insecticide resistance and the mosquito's ability to transmit malaria. Due to the sample size it was not possible to investigate the association between L1014Fmutation and sporozoite infection. Instead, this study assessed the association between L1014F-genotype with the sporozoite infection. 


\section{Methods}

\section{Study area and mosquito collections}

In 2008, four sentinel sites were established in Burkina Faso according to their different patterns of insecticide use and ecology. These sites include Goundry (rural Sahelian area with a low insecticide use), Koupela (Sahelian rural zone with moderate insecticide used), Soumousso (Sudan Savannah rural zone with rice and cotton cultivation using intensive insecticides) and Kuinima (urban area with intensive use of insecticide in agriculture). From these sites mosquito samples were collected, as previously described by Ranson et al. [11]. In each locality, a window exit trap was installed in five houses, with the homeowners' permission. Volunteers were trained to empty the trap daily into tubes containing silicagel. At the same time two pit-shelters were built in the site, consisting of a deep well with a straw roof, for collecting the outdoor-resting mosquitoes. Indoor pyrethroid spray catches (PSC) were also performed in ten randomly selected houses from each site once per month to sample indoor-resting mosquitoes. Mosquitoes were collected at the beginning of the rainy season (July-August) corresponding to the beginning of malaria transmission and at the end of rainy season (September-October), which corresponds to the high malaria transmission period.

\section{Species identification}

Mosquitoes were sorted morphologically according to the identification keys described by Edwards [30] for Culicine, and by Gillies and Coetzee [31] for Anopheline. All mosquitoes belonging to the An. gambiae complex were stored in silica gel to be used later for molecular analysis.

\section{Molecular analysis for Anopheles gambiae complex members' identification and Plasmodium falciparum antigen protein detection}

The head-thoraces from 2178 females An. gambiae sensu lato (s.l.) were used to assess for the presence of $P$. falciparum circumsporozoite protein (CSP) antigen according to method described by Wirtz et al. [32]. In addition to the ELISA-CSP detection, genomic DNA was extracted from the same individual mosquito samples and tested using a modified assay described by Paskewitz and Collins [33], then used for species identification, based on PCR-RFLP (restriction fragment length polymorphism) method described by Fanello et al. [34].

\section{Molecular detection of the L1014F mutation}

All ELISA positive samples (182 mosquitoes) and an equal number of negative samples randomly chosen within the same collection was genotyped for the L1014F $k d r$ mutation. The primers Agd1 (5'-ATAGATTCCCCG
ACCATG-3') and Agd3 (5'-AATTTGCATTACTTA CGACA-3') were used for the detection of the mutant 1014F allele whereas primers Agd2 (5'-AGACAAGGA TGATGAACC-3') and Agd4 (5'-CTGTAGTGATAG GAAATTTA-3') for the detection of the wild-type, 1014L allele [17]. The PCR program was $95^{\circ} \mathrm{C} / 5 \mathrm{~min} \times 1$ cycle, $\left(95{ }^{\circ} \mathrm{C} / 30 \mathrm{~s}, 46{ }^{\circ} \mathrm{C} / 30 \mathrm{~s}, 72{ }^{\circ} \mathrm{C} / 15 \mathrm{~s}\right) \times 35$ cycles, $72{ }^{\circ} \mathrm{C} / 5 \mathrm{~min} \times 1 \mathrm{cycle}$, and maintain at $4{ }^{\circ} \mathrm{C}$ after the PCR is completed.

\section{Data analysis}

All data analysis was performed using the Generalized Linear Mixed Effect Models (GLMMs) through the R statistical software version 3.5 .0 (2018-04-23) [35]. Model selection was based on Likelihood Ratio Tests (LRTs) using back-elimination, i.e. starting with a full model. The mean predicted values and 95\% confident intervals for significant terms were computed using the "effect" package [36].

\section{Mosquito species abundance}

As the abundance data were over-dispersed, the drivers of mosquito abundance were investigated through a negative binomial distribution. Here the mosquito counts were included as the response variable and site, collection method and year were used as explanatory factors. Because these factors are expected to differ among species, an interaction term of species with all three factors was included. Collection date and compound from which collection took place were added to the model as random effects.

\section{Sporozoite rate calculation}

The proportion of infected mosquitoes with $P$. falciparum sporozoites was modeled following a binomial distribution. This proportion was used as response variable whereas the species, site and method were included as explanatory variables. Collection date was used as a random effect.

Association between sporozoite rate and 1014F-genotypes To assess for the differences in resistance between infected and uninfected mosquitoes, a binomial distribution was used. Individuals mosquitoes were considered as resistance genotype (homozygote L1014F) or susceptible genotype (including heterozygote L1014F and homozygote $\mathrm{L} 1014 \mathrm{~L}$ ) since that the $k d r$ gene is recessive [37]. As the sporozoite rate was controlled by deliberately selecting an equal number that were infected and uninfected, genotype (RR) was used as a binary response variable and species while CSP were included as explanatory variable when controlling for method, year and site used as random effects variables. Due to the low number of 


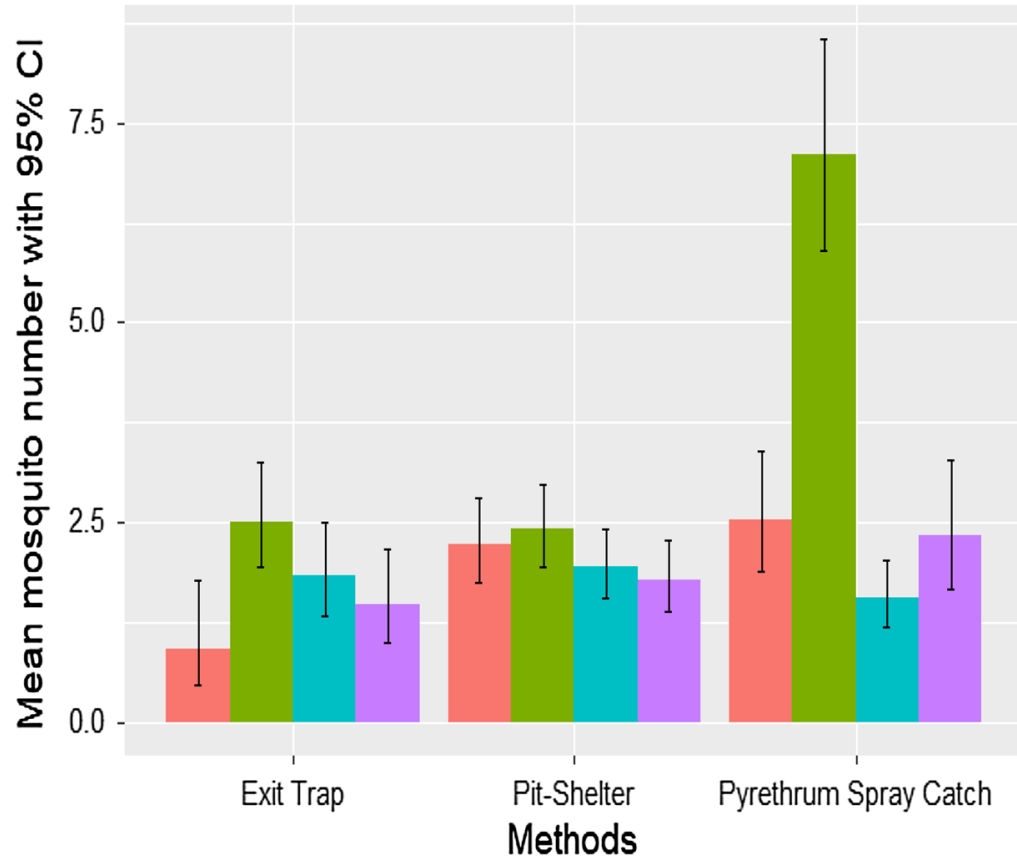

Species

An. funestus sp

An.gambiae s.l.

Culex sp

Other Anopheles sp

Fig. 1 Mean number of mosquitoes predicted by the model by methods and per species over sites and years

replicates, year, sites and trapping method were included as random effects.

\section{Results}

\section{Mosquito species abundance and composition}

From July 2008 to November 2010 10,938 mosquitoes were collected in the four sites. Of those, 9212 (84.22\%) were Anopheline, followed by Culex sp. 1678 (15.34\%), Aedes sp. 31 (0.33\%) and Mansonia sp. 11 (0.1\%). From the 9212 Anopheline collected, 6767 (73.46\%) were An. gambiae s.1., 1554 (16.87\%) were An. funestus and the remaining 891 (8.15\%) consisted of other Anopheline, including Anopheles brucei (0.22\%), Anopheles nili (0.79\%), Anopheles coustani (0.56\%), Anopheles pharoensis (0.22\%) and Anopheles rufipes (90.01\%). For the data analysis these latest species were grouped under 'other species' because of their low number. For the abundance data analysis, the final model included the three interactions between species and year, method and sites. The mean number of mosquitoes collected by each method in the study areas is shown in (Figs. 1, 2). The difference between methods of collection was statistically significant $\left(\chi^{2}=135.13\right.$, $\mathrm{df}=6, \mathrm{P}<0.001)$. Anopheles gambiae s.l. was the most abundant species observed in PSC and exit tap collection methods compared to An. funestus and other Anopheline (Additional file 1: Table S1). The ratio between An. gambiae s.l. and An. funestus was 0.379 in PSC $(\mathrm{P}<0.001)$ and 0.391 in exit traps $(P=0.04)$ collections, respectively. In contrast, there was no significant difference between $A n$. gambiae s.l. and An. funestus collected from the pit shelters with ratios of $0.979(\mathrm{P}>0.05)$.

\section{Anopheles gambiae complex species diversity according to collection methods, years and sites}

Molecular diagnostic assays showed that the An. gambiae complex includes An. arabiensis, An. coluzzii and $A n$. gambiae. The relative frequencies were $29.95 \%$ for $A n$. arabiensis $(\mathrm{n}=660), 25.78 \%$ for $A n$. coluzzii $(\mathrm{n}=568)$, and $40.80 \%$ for $A n$. gambiae $(\mathrm{n}=899)$, with a few number of hybrid An. gambiae/An. coluzzii 3.45\% $(\mathrm{n}=76)$. Anopheles gambiae was the most predominant $\left(\mathrm{X}^{2}=116.61, \mathrm{df}=6, \mathrm{P}<0.001\right)$ from each trapping method collection (Fig. 3).

Overall, there was a significant difference in species composition between the three collection methods when pooling data across all four sites, $\left(\mathrm{X}^{2}=115, \mathrm{P}<0.001\right.$ (Additional file 2: Table S2). In Goundry, An. arabiensis was the predominant species $(44.54 \%)$ with the higher proportion being collected by PSC followed by exit traps. In Koupela, the two predominant species were $A n$. coluzzii and $A n$. arabiensis, which were collected with similar proportions. However, in this area, An. arabiensis was found in higher proportion in exit traps followed by pit shelters and PSC, while An. coluzzii was more abundant in collections with PSC, followed by pit shelters and exit traps. In contrast, in Kuinima and Soumousso the predominant species was $A n$. gambiae in all years of the study. Overall, An. arabiensis and An. coluzzii fluctuated 


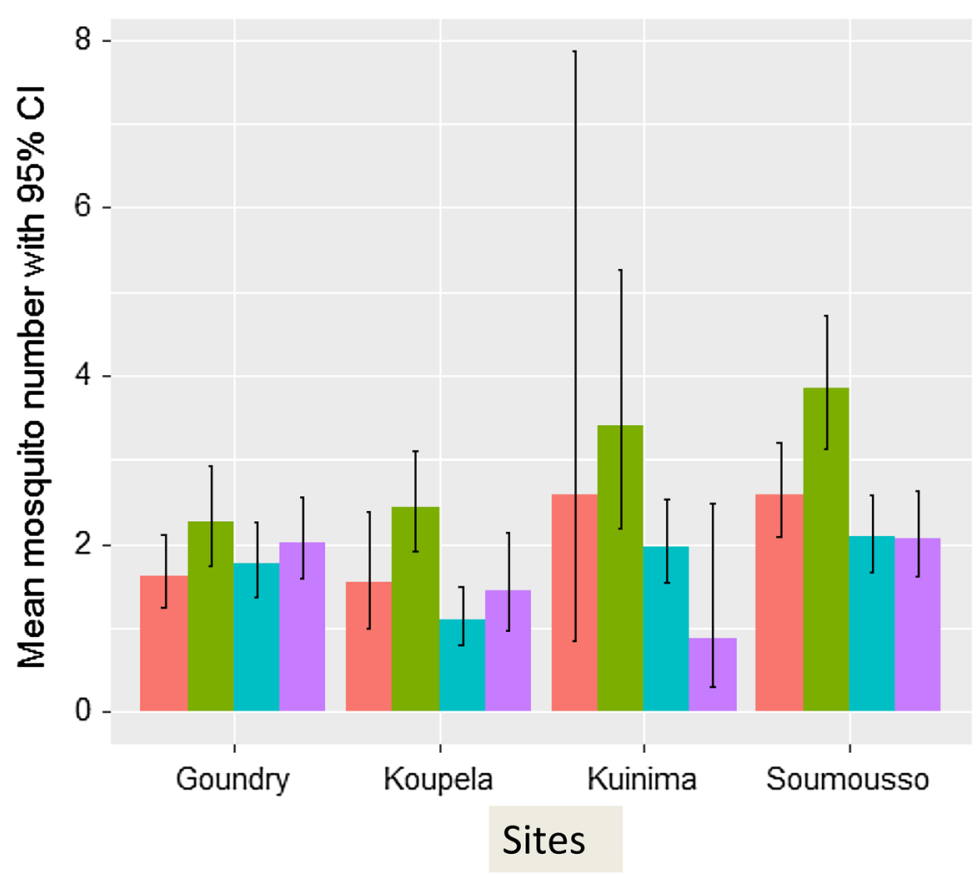

\section{Species}

An. funestus sp

An.gambiae s.l.

Culex sp

Other Anopheles sp

Fig. 2 Mean number of mosquitoes predicted by the model by sites and per species over tapping methods and years

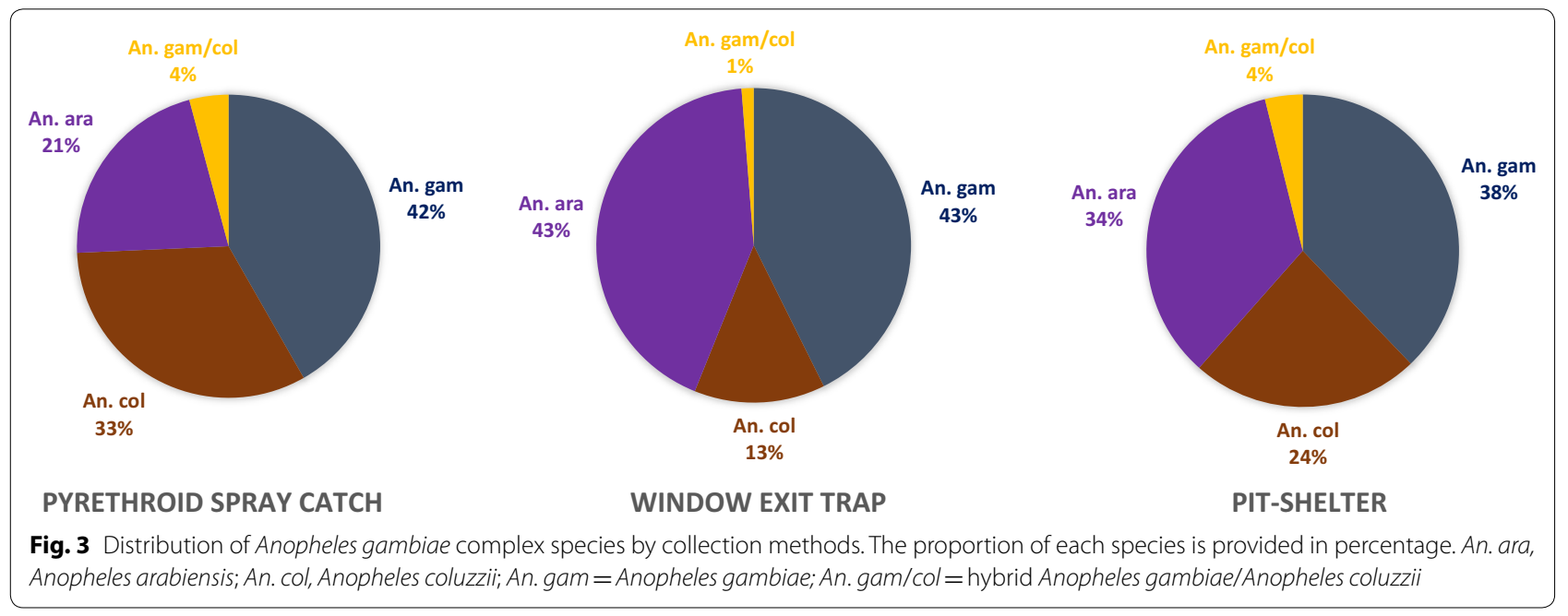

in the sudan sahelian (Koupela) and sahelian (Goundry) zones (Fig. 4).

\section{Plasmodium falciparum sporozoite rate in Anopheles gambiae populations}

The best model included site, methods and species as explanatory variables. 110 mosquitoes out of 2178 were tested positive for $P$. falciparum CSP antigen resulting in a mean sporozoite rate of 0.050 , (95\% CI 0.041-0.060) (Table 1). The P. falciparum sporozoite rate varied significantly between the four sites of study area (Fig. 5; $\mathrm{X}^{2}=16.642 \mathrm{df}=3, \mathrm{P}=0.001$ ), with the higher sporozoite rate of 0.065 , (95\% CI 0.039-0.108) observed in the site of Soumousso and the lower in Kuinima 0.010, (95\% CI 0.003-0.031). Between species the sporozoite rate was higher for An. gambiae 0.065, (95\% CI 0.049-0.083) compared to An. coluzzii 0.044, (95\% CI 0.029-0.064) and An. arabiensis 0.038, (95\% CI 0.025-0.055). However, there was no statistically significant difference of sporozoite rate between 


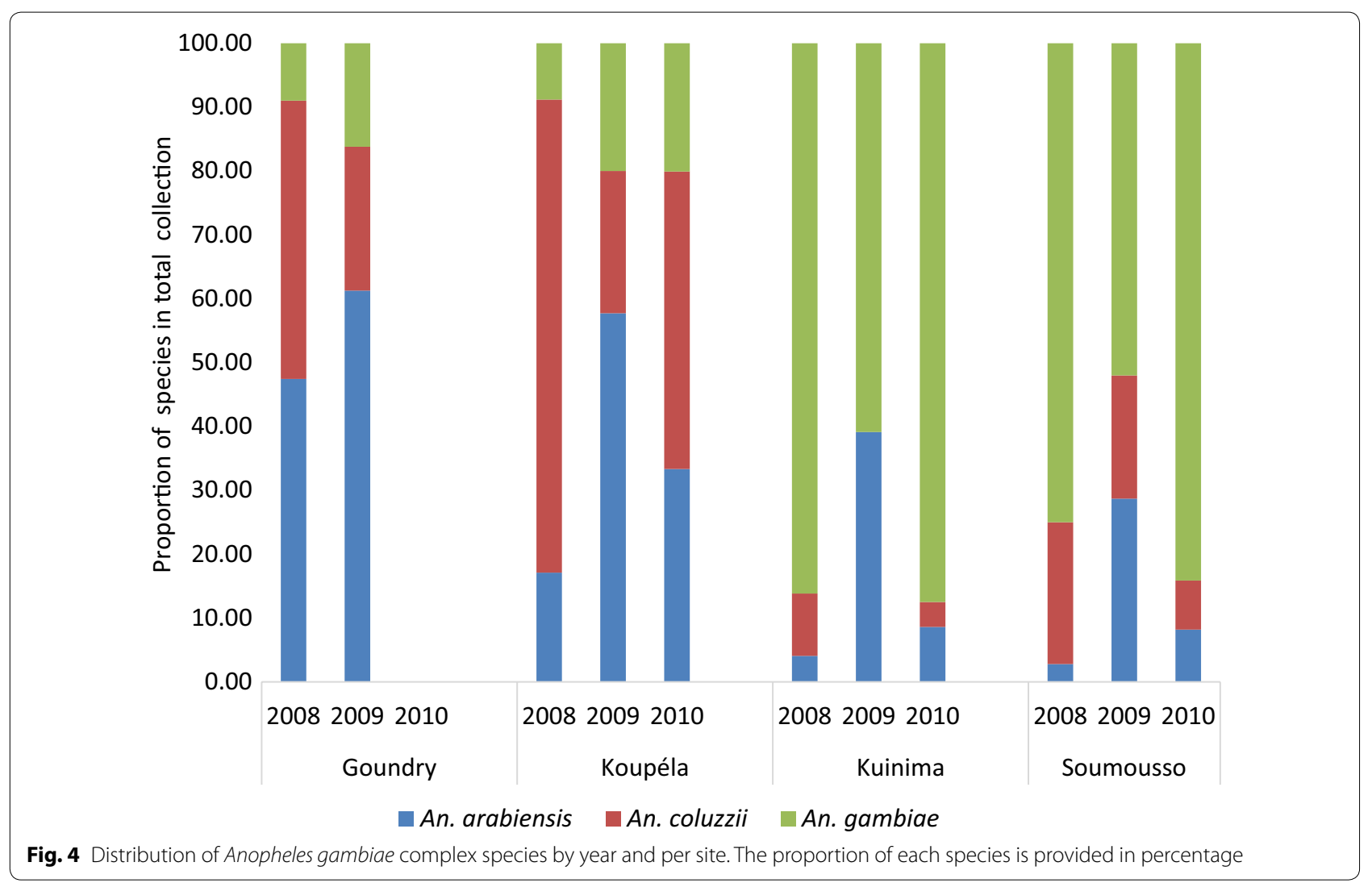

Table 1 Detection of CSP antigen in Anophelines collected in the four sites of study

\begin{tabular}{|c|c|c|c|c|c|c|c|c|c|c|}
\hline \multirow[t]{2}{*}{ Locality } & \multicolumn{2}{|c|}{ An. arabiensis } & \multicolumn{2}{|c|}{ An. coluzzii } & \multicolumn{2}{|c|}{ An. gambiae } & \multicolumn{2}{|c|}{ An. funestus } & \multicolumn{2}{|l|}{ Total } \\
\hline & Tested & $\mathrm{CSP}+$ & Tested & CSP+ & Tested & $\mathrm{CSP}+$ & Tested & CSP+ & Tested & CSP+ \\
\hline Goundry & 161 & 7 & 100 & 2 & 37 & 3 & 0 & 0 & 298 & 12 \\
\hline Koupéla & 334 & 5 & 333 & 10 & 140 & 13 & 0 & 0 & 807 & 28 \\
\hline Kuinima & 34 & 1 & 17 & 0 & 246 & 1 & 4 & 0 & 301 & 2 \\
\hline Soumousso & 128 & 12 & 120 & 13 & 477 & 42 & 47 & 1 & 772 & 68 \\
\hline Spz rate & $3.81 \%$ & & $4.39 \%$ & & $6.56 \%$ & & $1.96 \%$ & & $5.0 \%$ & \\
\hline Total & 657 & 25 & 570 & 25 & 900 & 59 & 51 & 1 & 2178 & 110 \\
\hline
\end{tabular}

species within the An. gambiae complex $\left(\chi^{2}=5.481\right.$, $\mathrm{df}=2, \mathrm{P}=0.065$ ).

The difference in infection rate between trapping methods was not statistically significant $\left(X^{2}=4.221\right.$, $\mathrm{df}=2, \mathrm{P}=0.121)$ but the sporozoite rate was highest in PSC collections (mean: 0.060, (95\% CI 0.047-0.076) and lowest in pit shelter collections (mean: $0.028,(95 \%$ CI $0.017-0.045)$. The $P$. falciparum sporozoite rate in exit traps was $0.056(95 \%$ CI $0.037-0.080)$.
Association between sporozoite rate and 1014F-genotype A total of 164 An. gambiae s.l. species were successfully genotyped for $k d r 1014 \mathrm{~F}$ allele, from which 92 were resistant (RR) and 72 susceptible (SS and RS) (Table 2). The best model includes only species as explanatory fixed effect of the $k d r$ resistant genotype $\left(x^{2}=64.242, \mathrm{df}=2\right.$, $\mathrm{P}<0.001)$. Therefore, the sporozoite infection status was not retained as a significant term $\left(\chi^{2}=0.031, \mathrm{df}=1\right.$, $\mathrm{P}=0.86$ ).

There was no significant difference in the proportion of RR between An. arabiensis and An. coluzzii (OR $=0.575$, $\mathrm{P}=0.555)$. In contrast there was a significant difference 


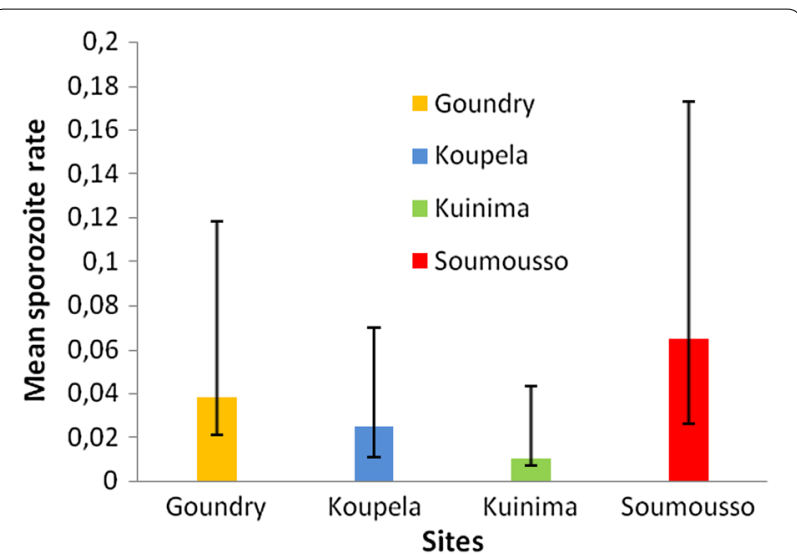

Fig. 5 Mean sporozoite rate predicted in the study areas (Goundry, Koupela, Kuinima and Soumousso)

Table 2 kdr genotype in An. gambiae s.l species collected in the four sites

\begin{tabular}{lccc}
\hline Species & Resistant & Susceptible & Total \\
\hline An. arabiensis & 9 & 39 & 48 \\
An. coluzzii & 13 & 27 & 40 \\
An. gambiae & 70 & 6 & 76 \\
Total & 92 & 72 & 164 \\
\hline
\end{tabular}

in this proportion when comparing An. arabiensis versus An. gambiae $(\mathrm{OR}=0.016, \mathrm{P}<0.001)$ and An. coluzzii versus An. gambiae (OR=0.028, $\mathrm{P}<0.001)$, (Fig. 6a, Additional file 3: Table S3).

In addition, the proportion of $k d r$ resistant genotype did not varied when comparing sporozoite infected vs uninfected within each species, $\left(X^{2}=0.035, P=0.85\right)$ for An. arabiensis, $\left(\chi^{2}=0.020, \mathrm{P}=0.88\right)$ for $A n$. coluzzii and $\left(\mathrm{x}^{2}=0.006, \mathrm{P}=0.93\right)$ for An. gambiae (details are shown in Table 3).

Furthermore, within the sporozoite-infected sub-group the predicted proportion of resistant genotype was 0.52 , with (95\% CI 0.19-0.83) whilst 0.49, with (95\% CI 0.190.81 ) within the uninfected (Fig. 6b).

\section{Discussion}

The present study shows that An. gambiae s.l. is the most predominant malaria vector within the study area. Molecular identification showed that An. gambiae s.l. consists of the three species An. gambiae sensu stricto, An. coluzzii and An arabiensis and that there is a significant difference in their proportion between the sites within the study area. Anopheles arabiensis was the most abundant species occurring in Goundry, but found at the similar frequency as An. Coluzzii in Koupela. In the southern areas (Kuinima and Soumousso) An. gambiae s.s was the most predominant species followed by $A n$. arabiensis. These findings are in agreement with previous studies suggesting that An. gambiae s.s., An coluzzii and $A n$. arabiensis are the most widespread malaria vectors across Burkina Faso [6, 7]. However, the relative frequency of these species varied according to ecological settings. Furthermore, a significant reduction was found in the An. arabiensis proportion in 2008 from sample collected as adults within all sites particularly in Koupela, Kuinima and Soumousso compare to proportion from sample collected as larvae and reared to adulthood in laboratory conditions and described in Badolo et al. [10]. The missing proportion of An. arabiensis was subsequently filled mainly by An. gambiae s.s. in Soumousso and Kuinima and by An. coluzzii in Koupela and Goundry. The observed variation in species composition between larvae and adult populations may be partially due to the high susceptibility of An. arabiensis to insecticides as also suggested by the bioassay results described elsewhere showing an association between the 1014F-genotype and mosquito survival to permethrin and DDT [10]. This may be indicative of the effect of insecticide resistance on species composition according to insecticide use within a given area.

Complementary trapping methods were used to collect a representative sample of Anopheles gambiae complex mosquitoes with reference to resting behaviour. The results show a significant difference in species composition between these collection methods. In most cases, the three species from the An. gambiae complex were abundantly caught inside houses. An important fraction of this population was also found in exit traps and pit shelters. More specifically, An. arabiensis predominated in outdoor collection (window exit trap and pit shelters). This behaviour of An. arabiensis is consistent with previous studies showing that An. arabiensis are more generalist in terms of host choice and resting behaviour due to phenotypic plasticity [38].

Vector species with a relatively broad host range, like An. arabiensis, are thought to be better able to persist in areas of high indoor insecticide use. In contrast, $A n$. coluzzii was caught in higher abundances in PSC. The PSC is intended to collect mosquitoes that feed and rest indoors or feed outdoors and indoors (endophilic mosquitoes), therefore, it may be less sensitive in collecting species that predominantly rest outdoors [39], compared to exit traps and pit shelters that target outdoor-resting mosquitoes. Anopheles funestus was highly caught indoor using PSC and outdoor in pit shelters. This finding is in agreement with previous studies on An. funestus population from Burkina Faso describing two chromosomal forms with different resting behaviour patterns: one form 


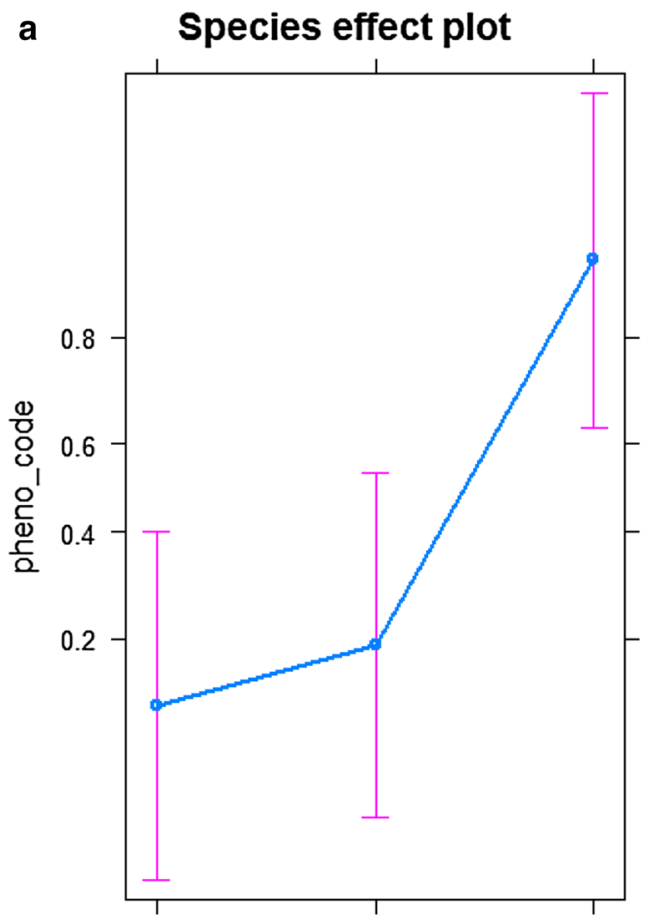

An. arabiensis

An. coluzzii

An. gambiae

Species

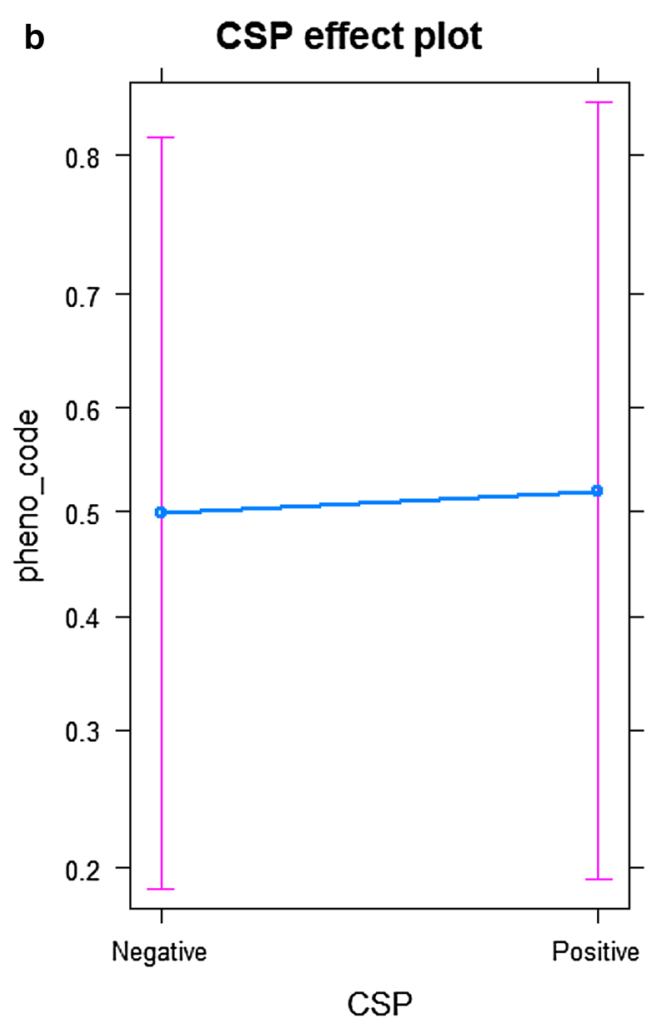

Fig. 6 The effects of An. gambiae s.l. species composition (a) and the proportion of kdr resistant genotype in CSP-positive and CSP-negative mosquito's (b)

Table 3 Relative proportions of kdr 1014F-genotype with $95 \% \mathrm{Cl}$ in CSP + and CSP- mosquitoes for An. arabiensis, An. coluzzii and An. gambiae

\begin{tabular}{|c|c|c|c|c|c|c|c|}
\hline \multirow[t]{2}{*}{ Status } & \multirow{2}{*}{$\begin{array}{l}\text { Species } \\
\mathbf{n}\end{array}$} & \multicolumn{2}{|l|}{ An. arabiensis } & \multicolumn{2}{|l|}{ An. coluzzii } & \multicolumn{2}{|l|}{ An. gambiae } \\
\hline & & Resistant & Susceptible & Resistant & Susceptible & Resistant & Susceptible \\
\hline CSP-negative & 98 & $6.12 \%(2.27-12.85)$ & $26.54 \%(18.12-36.4)$ & $8.16 \%$ (3.59-15.45) & $20.41 \%(12.93-29.74)$ & $35.71 \%(26.28-46.02)$ & $3.06 \%(0.63-8.68)$ \\
\hline CSP-positive & 66 & $4.54 \%(0.94-12.71)$ & $19.69 \%(10.92-31.32)$ & $7.57 \%(2.5-16.8)$ & $10.6 \%(4.37-20.63)$ & $53.03 \%(40.34-65.43)$ & $4.54 \%(0.94-12.71)$ \\
\hline$K d r$ frequency & & $11.44 \%(2.5-39.85)$ & & $19.20 \%(4.53-53.73)$ & & $89.90 \%$ (63.14-97.45) & \\
\hline
\end{tabular}

was mainly exophilic and the second endophilic [40]. The current study shows significant difference in resting behaviour between An. arabiensis and the two other species, An. coluzzii and An. gambiae s.s., depending on the geographical location. Meanwhile the efficacy of vector control intervention based on IRS may be affected by this behaviour. This result is aligned with previous findings showing that An. arabiensis was more exophilic, exophagic and zoophilic than An. gambiae s.s [41].

Following Badolo et al. [10], one of the aims of this study was also to investigate the association between the $k d r$ 1014F-genotype and the infection status. The results from this study showed that P. falciparum sporozoite rate varied significantly between the four study sites [10]. Based on laboratory experiments, Ndiath et al. [42] suggested that An. coluzzii was less susceptible to P. falciparum infection than An. gambiae s.s, while Gneme et al. [43] found that in Burkina Faso An. gambiae s.s. and An. coluzzii were equally susceptible to $P$. falciparum infection. Additionally, previous field studies from Burkina Faso [6] and Senegal [44] reported no difference in sporozoite rate between An. gambiae s.s. and An. coluzzii confirming the findings of the present study. Furthermore, a high proportion of homozygote mosquito to 1014F-genotype was found here in the sporozoite-infected mosquito sub-group compared to uninfected group, but 
there was no statistical difference suggesting that variation in resistance genotype proportion is not associated with the infection status. The current findings do not support the work from Alout et al. [23], who showed that $A n$. gambiae mosquitoes with $k d r$ alleles are more susceptible to Plasmodium than insecticide susceptible mosquitoes, and also contrast with the findings in Senegal, Burundi and Tanzania, which reported a significant correlation between the 1014F-genotype and the infection with $P$. falciparum [45-47]. This disagreement could be explained by the small sample size of this study which may limit the power to infer this relationship. The small sample size in this study also limited the comparison of the 1014F-genotype frequencies from mosquito collected as larvae versus those collected as adults. So, the results may have been different when increasing the samples size to those of Kabula et al. [47], who tested 526 specimens.

\section{Conclusion}

The present study showed the diversity of malaria vectors species composition and significant variations in the $k d r$ resistance genotype between vector species. However, associations were not found between 1014F-genotype and $P$. falciparum sporozoite infection status in Burkina Faso. Further work with a larger sample size of wildcaught mosquitoes is needed to establish the relationship between insecticide resistance in An. gambiae and ability to transmit $P$. falciparum in Burkina Faso, in the context of increasing malaria cases from year-to-year despite the scaling-up of the LLINs by the National Malaria Control Programme (NMCP).

\section{Additional files}

Additional file 1: Table S1. The contrast in mean number of mosquito collected in each trap and the ratios between species, standard errors, z ratios and the p-values.

Additional file 2: Table S2. Species composition and relative frequency of the An. gambiae complex members by collection method and sites.

Additional file 3: Table S3. Ccomparison of the kdr resistant phenotype between species, p-values adjusted according to tukey methods.

\section{Abbreviations}

CSP: circum-sporozoite protein; DNA: deoxyribonucleic acid; DDT: dichlorodiphenyl ethane; ELISA: enzyme linked immuno-sorbent assay; GLMMs: generalized linear mixed effect models; TNs: insecticide-treated nets; IRS: indoor residual spraying; Kdr: knockdown resistance; LLINs: long-lasting insecticide-treated nets; OR: odds ratio; PCR: polymerase chain reaction; PSC: pyrethroid spray catch

\section{Authors' contributions}

HR and NFS conceived and designed the study. AT, SA, AB, NFS and HR drafted the manuscript. MV, LN, AS and AT analysed the data. AT, AB, AS, MWG, ZS and HKT oversaw field collection and laboratory work. All authors read and approved the final manuscript.

\section{Author details}

${ }_{1}^{1}$ Centre National de Recherche et de Formation sur le Paludisme, 01 BP 2208 Ouagadougou 01, Burkina Faso. ${ }^{2}$ Laboratoire d'Entomologie Fondamentale et Appliquée, Université Ouaga1 Pr Joseph Ki-Zerbo, BP 7021 Ouagadougou 03, Burkina Faso. ${ }^{3}$ Department of Vector Biology, Liverpool School of Tropical Medicine, Pembroke Place, Liverpool L3 5QA, UK. ${ }^{4}$ Institute of Biodiversity, Animal Health and Comparative Medicine, College of Medical, Veterinary and Life Sciences, University of Glasgow, University Avenue, Glasgow G12 8QQ, UK.

\section{Acknowledgements}

This study received financial support from the UNICEF/UNDP/World Bank/ WHO Special Programme for Research and Training in Tropical Diseases (WHO/ TDR) through the grant A70588 to Hilary Ranson. We would like to acknowledge the support of Frederic Simard, Vincent Corbel, RochDabiré, Filomeno Fortes and Joao Pinto, who contributed towards the establishment of the WHO/TDR network supported its activities. MV is funded by the MRC/DFID Concordat agreement and EDCTP2 (MR/N015320/1).

\section{Competing interests}

The authors declare that they have no competing interests.

Availability of data and materialS

Not applicable.

Consent for publication

Not applicable.

Ethics approval and consent to participate

Not applicable.

\section{Funding}

This study received financial support from the UNICEF/UNDP/World Bank/ WHO Special Programme for Research and Training in Tropical Diseases (WHO/ TDR) through the grant A70588 to Hilary Ranson.

\section{Publisher's Note}

Springer Nature remains neutral with regard to jurisdictional claims in published maps and institutional affiliations.

Received: 24 August 2018 Accepted: 23 April 2019

Published online: 08 May 2019

\section{References}

1. who. World malaria report 2018. Geneva: World Health Organization; 2018.

2. Direction generale des statistiques sectorielles. Annuaire statistique 2017; p. 386. 2018. http://cns.bf/IMG/pdf/annuaire_2017_du_ms.pdf.

3. Robert V, Gazin P, Boudin C, Molez JF, Ouedraogo V, Carnevale P. La transmission du paludisme en zone de savane arborée et en zone rizicole des environs de Bobo-Dioulasso (Burkina Faso). Ann Soc belge Med Trop. 1985;65:201-14.

4. Dabiré RK, Baldet T, Diabate A, Dia I, Costatini C, Cohuet A, et al. Anopheles funestus (Diptera, Culicidae) in a humid savannah area of Western Burkina Faso: bionomics, insecticide resistance status. J Med Entomol. 2007:44:990-7.

5. Costantini C, Ayala D, Guelbeogo WM, Pombi M, Some CY, Bassole IHN, et al. Living at the edge: biogeographic patterns of habitat segregation conform to speciation by niche expansion in Anopheles gambiae. BMC Ecol. 2009;9:16.

6. Dabiré RK, Namountougou M, Sawadogo SP, Yaro LB, Toé KH, Ouari A, et al. Population dynamics of Anopheles gambiae s.l. in Bobo-Dioulasso cit: bionomics, infection rate and susceptibility to insecticides. Parasit Vectors. 2012;5:127

7. Diabaté A, Brengues C, Baldet T, Dabiré KR, Hougard JM, Akogbeto M, et al. The spread of the Leu-Phe kdr mutation through Anopheles gambiae complex in Burkina Faso: genetic introgression and de novo phenomena. Trop Med Int Health. 2004;9:1267-73. 
8. Fournet F, Cussac M, Ouari A, Meyer P, Toé KH, Gouagna L, et al. Diversity in anopheline larval habitats and adult composition during the dry and wet seasons in Ouagadougou (Burkina Faso). Malar J. 2010;9:78.

9. Riehle MM, Guelbeogo WM, Gneme A, Eiglmeier K, Holm I, Bischoff E, et al. A cryptic subgroup of Anopheles gambiae is highly susceptible to human malaria parasites. Science. 2011;331:596-8.

10. Badolo A, Traore A, Jones CM, Sanou A, Flood L, Guelbeogo WM, et al. Three years of insecticide resistance monitoring in Anopheles gambiae in Burkina Faso: resistance on the rise? Malar J. 2012:11:232.

11. Ranson H, Abdallah H, Badolo A, Guelbeogo WM, Kerah-Hinzoumbé C, Yangalbé-Kalnoné $\mathrm{E}$, et al. Insecticide resistance in Anopheles gambiae: data from the first year of a multi-country study highlight the extent of the problem. Malar J. 2009;8:299.

12. Namountougou M, Simard F, Baldet T, Diabaté A, Ouédraogo JB, Martin T, et al. Multiple insecticide resistance in Anopheles gambiae s.l. populations from Burkina Faso, West Africa. PLoS One. 2012;7:0048412.

13. Toé KH, Jones CM, N'Fale S, Ismail HM, Dabiré RK, Ranson H. Increased pyrethroid resistance in malaria vectors and decreased bed net effectiveness, Burkina Faso. Emerg Infect Dis. 2014;20:1691-6.

14. Yadouleton A, Baba-moussa L, Klotoe JR, Coulibaly T, Carine T, Tossou $R$, et al. Detection of multiple insecticide resistance mechanisms in Anopheles gambiae s.l. populations from the vegetable farming area of Houeyiho, Southern Benin, West Africa. Int J Mosq Res. 2018;5(3):21-7.

15. Thiaw $O$, Doucouré $S$, Sougoufara $S$, Sougoufara $S$, Bouganali $C$, Konaté $L$, et al. Investigating insecticide resistance and knock-down resistance $(\mathrm{kdr})$ mutation in Dielmo, Senegal, an area under longlasting insecticidal treated nets universal coverage for 10 years. Malar J. 2018;17:123.

16. Donnelly MJ, Simard F, Lehmann T. Evolutionary studies of malaria vectors. Trends Parasitol. 2002;18:75-80.

17. Martinez-Torres D, Chandre F, Williamson MS, Darriet F, Bergé JB, Devonshire AL, et al. Molecular characterization of pyrethroid knockdown resistance $(\mathrm{kdr})$ in the major malaria vector Anopheles gambiae ss. Insect Mol Biol. 1998;7:179-84.

18. Ranson H, Jensen B, Vulule JM, Wang X, Hemingway J, Collins FH. Identification of a point mutation in the voltage-gated sodium channel gene of Kenyan Anopheles gambiae associated with resistance to DDT and pyrethroids. Insect Mol Biol. 2000;9:491-7.

19. Jones CM, Liyanapathirana M, Agossa FR, Weetman D, Ranson H, Donnelly $\mathrm{MJ}$, et al. Footprints of positive selection associated with a mutation (N1575Y) in the voltage-gated sodium channel of Anopheles gambiae. Proc Natl Acad Sci USA. 2012;109:6614-9.

20. Kwiatkowska RM, Platt N, Poupardin R, Irving H, Dabire RK, Mitchell S, et al. Dissecting the mechanisms responsible for the multiple insecticide resistance phenotype in Anopheles gambiae s.s., M form, from Vallée du Kou, Burkina Faso. Gene. 2013;519:98-106.

21. who. Global plan for insecticide resistance management in malaria vectors. Geneva: World Health Organization; 2012.

22. McCarroll L, Hemingway J. Can insecticide resistance status affect parasite transmission in mosquitoes? Insect Biochem Mol Biol. 2002;32:1345-51.

23. Alout H, Ndam NT, Sandeu MM, Djogbénou I, Chandre F, Dabiré RK, et al. Insecticide resistance alleles affect vector competence of Anopheles gambiae s.s. for Plasmodium falciparum field isolates. PLoS One. 2013;8:e63849.

24. Jones CM, Sanou A, Guelbeogo WM, Sagnon N, Johnson PC, Ranson $H$. Aging partially restores the efficacy of malaria vector control in insecticide-resistant populations of Anopheles gambiae s.l. from Burkina Faso. Malar J. 2012;11:24.

25. Glunt KD, Thomas MB, Read AF. The effects of age, exposure history and malaria infection on the susceptibility of Anopheles mosquitoes to low concentrations of pyrethroid. PLOS ONE. 2011;6:e24968.

26. Lines JD, Nassor NS. DDT resistance in Anopheles gambiae declines with mosquito age. Med Vet Entomol. 1991;5(3):261-5.

27. Rajatileka S, Burhani J, Ranson H. Mosquito age and susceptibility to insecticides. Trans R Soc Trop Med Hyg. 2011;105:247-53.

28. Viana M, Hughes A, Matthiopoulos J, Ranson H, Ferguson HM. Delayed mortality effects cut the malaria transmission potential of insecticideresistant mosquitoes. Proc Natl Acad Sci USA. 2016;113:8975-80.
29. Mitri C, Markianos K, Guelbeogo WM, Bischoff E, Gneme A, Eiglmeier K, Holm I, Sagnon NF, Vernick KD, Riehle MM. The kdr-bearing haplotype and susceptibility to Plasmodium falciparum in Anopheles gambiae: genetic correlation and functional testing. Malar J. 2015;14:391.

30. Edwards FW. Mosquitoes of the ethiopian region. III. Culicine adults and pupae. London: British. Museum (Nat. Hist.); 1941. p. 513.

31. Gillies MT, Coetzee M. A supplement to the Anophelinae of Africa south of the Sahara (Afrotropical Region). Johannesburg: South African Institute for Medical Research; 1987.

32. Wirtz RA, Zavala F, Charoenvit Y, Campbell GH, Burkot TR, Schneider I, et al. Comparative testing of monoclonal antibodies against Plasmodium falciparum sporozoites for ELISA development. Bull World Health Organ. 1987;65:39-45.

33. Paskewitz SM, Collins FH. Use of the polymerase chain reaction to identify mosquito species of the Anopheles gambiae complex. Med Vet Entomol. 1990:4:367-73

34. Fanello C, Santolamazza F, Della Torre A. Simultaneous identification of species and molecular forms of the Anopheles gambiae complex by PCRRFLP. Med Vet Entomol. 2002;16:461-5.

35. Crawley MJ. The R book. New York: Wiley; 2012. p. 951.

36. Fox J. Effect displays in R for generalised linear models. J Stat Soft. 2003:8:15.

37. Pinto J, Lynd A, Vicente LJ, Santolamazza F, Randle NP, Gentile G, et al. Multiple origins of knockdown resistance mutations in the Afrotropical mosquito vector Anopheles gambiae. PLoS ONE. 2007;2:e1243.

38. Main BJ, Lee Y, Ferguson HM, Kreppel SK, Kihonda A, Govella NJ, et al. The genetic basis of host preference and resting behavior in the major African malaria vector, Anopheles arabiensis. PLoS Genet. 2016;12:e1006303.

39. Mboera LEG. Sampling techniques for adult Afrotropical malaria vectors and their reliability in the estimation of entomological inoculation rate, Tanzan. Health Res Bull. 2005;7:117-24.

40. Guelbeogo WM, Sagnon NF, Liu F, Besansky NJ, Costantini C. Behavioural divergence of sympatric Anopheles funestus populations in Burkina Faso. Malar J. 2014;13:65

41. Chandre F, Manguin S, Brengues C, Dossou Yovo J, Darriet F, Diabate A, et al. Current distribution of a pyrethroid resistance gene $(k d r)$ in Anopheles gambiae complex from West Africa and further evidence for reproductive isolation of the Mopti form. Parassitologia. 1999;41:319-22.

42. Ndiath MO, Cohuet A, Gaye A, Konaté L, Mazenot C, Faye O, et al. Comparative susceptibility to Plasmodium falciparum of the molecular forms M and S of Anopheles gambiae and Anopheles arabiensis. Malar J. 2011:10:269.

43. Gneme A, Guelbeogo WM, Riehle MM, Sanou A, Traore A, Zongo S, et al. Equivalent susceptibility of Anopheles gambiae M and S molecular forms and Anopheles arabiensis to Plasmodium falciparum infection in Burkina Faso. Malar J. 2013:12:204

44. Ndiath MO, Brengues C, Konate L, Sokhna C, Boudin C, Trape JF, et al. Dynamics of transmission of Plasmodium falciparum by Anopheles arabiensis and the molecular forms $\mathrm{M}$ and S of Anopheles gambiae in Dielmo, Senegal. Malar J. 2008;7:136

45. Protopopoff N, Verhaeghen K, Van Bortel W, Roelants P, Marcotty T, Baza D, et al. A significant increase in $\mathrm{kdr}$ in Anopheles gambiae is associated with an intensive vector control intervention in Burundi highlands. Trop Med Int Health. 2008;13:1479-87.

46. Ndiath MO, Cailleau A, Diedhiou SM, Gaye A, Boudin C, Richard V, et al. Effects of the $k d r$ resistance mutation on the susceptibility of wild Anopheles gambiae populations to Plasmodium falciparum: a hindrance for vector control. Malar J. 2014;13:340.

47. Kabula B, Tungu P, Rippon EJ, Steen K, Kisinza W, Magesa S, et al. A significant association between deltamethrin resistance, Plasmodium falciparum infection and the Vgsc-1014S resistance mutation in Anopheles gambiae highlights the epidemiological importance of resistance markers. Malar J. 2016;15:289. 